\title{
STRATEGI PENGEMBANGAN OBJEK WISATA ASRAMA INGGRISAN SEBAGAI HERITAGE TOURISM DI KABUPATEN BANYUWANGI
}

\author{
Eka Afrida Ermawati ${ }^{1}$, Adetiya Prananda Putra ${ }^{2}$ \\ Politeknik Negeri Banyuwangi \\ email: ekaafrida22@poliwangi.ac.id ${ }^{1}$
}

\begin{abstract}
Abstrak
Tujuan penelitian ini adalah menyusun strategi pengembangan obyek wisata Asrama Inggrisan sebagai daya tarik heritage tourism di Banyuwangi.Metode penelitian yang digunakan adalah deskriptip kualitatif dengan evaluasi faktor insternal dan eksternaal (IFE) dan (EFE), matrik internal external (IE) dan matrik SWOT. Strategi pengembangan yang dihasilkan antara lain mengembangan Asrama Inggrisan sebagai ikon tujuan heritage tourism; memanfaatkan bangunan Asrama Inggrisan sebagai sarana dan media edukasi bukti peninggalan stasiun kabel telegraf bawah laut zaman Belanda; menjalin kerjasama antara Pemkab Banyuwangi dengan Departemen Pertahanan TNI-AD, komunitas sejarahwan, masyarakat lokal, guide dan sektor bisnis untuk mengoptimalkan dan memperhatikan pengelolaan guna menjaga kelestarian obyek wisata heritage; melakukan revitalisasi Asrama Inggrisan untuk menjaga aset peninggalan heritage;mencipakan sinergisme dalam pengelolaan dan pelestarian cagar budaya Asrama Inggrisan; menggali lebih dalam potensi sejarah yang ada untuk diwujudkan menjadi atraksi wisata yang berbeda; menghimbau masyarakat maupun pengunjung untuk tidak melakukan perusakan/vandalism; melaksanakan workhsop/lokakarya perspektif untuk pengelolaan dan pengembangan Asrama Inggrisan sebagai penunjang kegiatan wisata heritage; melengkapi fasilitas, sarana dan prasarana untuk menunjang kegiatan wisata heritage; dan mengoptimalkan perawatan dan pengelolaan bangunan Asrama Inggrisan.
\end{abstract}

Kata kunci: Heritage Tourism, Banyuwangi, SWOT

\begin{abstract}
The purpose of this research is to develop a development strategy for Asrama Inggrisan as an attraction for heritage tourism in Banyuwangi. The research method used is descriptive qualitative with IFE, EFE, IE and SWOTmatrix. The resulting development strategies include developing Asrama Inggrisan as an icon of heritage tourism destinations; utilizingAsrama Inggrisan building as a means and media for educational evidence of the legacy of the undersea telegraph cable station under the Dutch era; establishing cooperation between Banyuwangi Regency Government and Indonesian Army Defense Department, the historian community, local communities, guides and the business sector to optimize and pay attention to management in order to preserve heritage tourism objects; revitalizing Asrama Inggrisan to protect heritage assets; creating synergism in the management and preservation of cultural heritage of British House; exploring historical heritage and manifest it in the form of unique tourist attractions; urging the public and visitors not to commit vandalism; carrying out workhsopfor the management and development of Asrama Inggrisan to support heritage tourism activities; completing facilities, and infrastructure to support heritage tourism activities; and optimizing the maintenance and management of Asrama Inggrisan.
\end{abstract}

Keywords: Heritage Tourism, Banyuwangi, SWOT. 


\section{INTRODUCTION}

Indonesia memiliki Kekayaan dalam hal wisata sejarah. Hal itu dapat dilihat dari keberagaman peninggalan yang ada sejak masa Pra-sejarah hingga Penjajahan Jepang. Tidak sedikit dari wilayah indonesia yang memiliki sejarah perjalannya sendiri, seperti Bandung, Surabaya, Semarang dan Makassar. Di Provinsi Jawa Timur, selain kota Surabaya yang terkenal dengan sebutan Kota Pahlawan, terdapat juga Kabupaten yang mulai mengoptimalkan potensi pariwisata alam dan budayanya yaitu Kabupaten Banyuwangi.

Dalam sejarahnya, Banyuwangi merupakan wilayah kerajaan Blambangan. Dalam Sejarah tersebut terdapat kisah tentang Asrama Inggrisan yang dibangun pada tahun 1811 sampai dengan tahun 1816 oleh Letnan Kolonel Meycin S.Y. Kompleks Asrama Inggrisan tersebut terletak di tengah kota bersebrangan dengan Taman Blambangan yang dulunya bernama Tagal Lodge.

Stasiun Kabel Telegraf bawah laut menjdi salah satu sisa sejarah yang ada di asrama Inggrisan. Stasiun ini menjadi penghubung antara Australia dengan Asia dan Eropa untuk melakukan komuniksi jarak jauh. Kabel telegram tersebut membentang dari Banyuwangi ke Darwin, Australia. Berikutnya. Seteah indonesia merdeka, Asrama Inggrisan kemudian dimanfaatkan sebagai tempat istirahat Batalion Macan Putih. Hingga pada tahun 1949 terakhir kali tempt ini dipakai oleh Batalion 510 . Sekarang, tempat ini beralih fungsi menjadi rumah dinas anggota Kodim 0825 Banyuwangi.

Keaslian bangunan asrama inggrisan dan sejarah yang melekat padanya menjadikan asrama ini berpotensi menjadi salah heritage tourismyang masih ada di Banyuwangi. (Pitana, 2005) menyebutkan bahwa salah satu komponen vital bagi seseorang untuk mendatangi sebuah destinasi wisata adalah daya tarik tempat itu sendiri.

Sedangkan daya tarik dari sebuah Heritage tourism adalah warisan dan peninggalan sejarahnya. Heritage tourism juga dapat dikatakansebuah perpaduan pribadi dengan tradisi, sejarah dan budaya. Heritage tourism didasarkan pada konsep bahwa setiap komunitas memiliki cara sendiri untuk menceritakan (Burns et al, 2010) Keberadaan heritage tourism di Banyuwangi saat ini semakin tersingkir dan terlupakan akibat modernisasi yang terjadi. Padahal apabila dikelola dan dimanfaatkan secara tepat, tidak menutup kemungkinan heritage tourism dapat menjadi sumber pendapatan daerah yangdapat mendukung pertumbuhan perekonomian Banyuwangi.

Pengembangan pariwisata merupakan suatu aktivitas yang bertujuan untuk mengembangkan ataupun memperbaiki suatu destinasi wisata agar menarik minat wisatawan untuk datang mengunjunginya (Baretto dan Giantari, 2015). Rozaan, et al (2018) menambahkan bahwa Heritage Tourismmerupakan kegiatan berwisata yaeng memiliki tujuan untuk mengetahui keotentikan sejarah suatu tempat dan unsur-unsur yang ada didalamnya.

Pengembangan destinasi wisata sejarah juga harus melibatkan para pemangku kepentingan khususnya pemerintah daerah yang bertugas sebagai pelestari budaya dan sejarah daerah. Rahman (2013) dalam penelitian yang berjudul heritage management challengesin historic town of Ludlow England menunjukkan bahwa pentingnya peran pemangku kepentingan utama dalam mengelola dan mempromosikan heritage tourism.

Penyusunan strategi pengembangan obyek wisata Asrama Inggrisan sebagai daya tarik heritage tourism di Kabupaten Banyuwangi sehingga dapat menawarkan alternative destinasi bagi wisatawan selain wisata budaya dan alam menjadi tujuan utama dari penelitian ini .

\section{METODOLOGI}

Penelitian ini berbentuk deskriptif kualitatif yang memakai pendekatan studi kasus untuk menjawab permasalahan yang ada.Pendekatan 
studi kasus dipilih agar hasil yang didapat nantinya dapat mendeskripsikan dengan jelas fenomena yang terjadi pada sebuah lingkungan secara sistematis dan nyata (Sulastri, et. al., 2018).

Data primer dari penelitian ini diperoleh lewat metode in-depth interview terhadap kabid pengembangan Dinas Kebudayaan dan Pariwisata Kabupaten Banyuwangi, ketua komunitas Banjoewangie Tempoe Doeloe, ketua komunitas pecinta sejarah Banyuwangi, dosen Politeknik Negeri Banyuwangi, tokoh masyarakat setempat, dan wisatawan yang pernah berkunjung ke Asrama Inggrisan. Pemilihan narasumber berdasarkan pada pertimbangan bahwanarasumber merupakan pihak-pihak yang secara langsung terlibat pada pengelolaan dan pengembangan destinasi wisata kampong Inggrisan.Sedangkan data sekunder pada penelitian ini diperoleh leat studi kepustakaan.

Tujuan inti dari penelitian ini adalah pengembangan destinasi wisata Asrama Inggrisan sebagai Heritage Tourism di kabupaten Banyuwangi. Analisi faktor faktor eksternal dan internal dilakukan menggunakan matrik IFE dan EFE. Kemudian, penerapan matrik IE digunakan untuk melakukan analisis posisi dari hasil tersebut kemudian disusunlah alternatif strategi yang nantinya akan dipakai sebagai sarana pengembangan Asrama Inggrisan menggunakan Analisis SWOT. Sesuai dengan apa yang direkomendasikan oleh Chan, (2011). Hasil analisis tersebut nantinyaakan digunakan untuk pengembangan Asrama Inggrisan secara berkesinambungan.

\section{RESULT AND DISCUSSION Evaluasi Faktor Internal}

Analisis faktor internal diimplementasikan untuk untuk mengidentifikasi dan mengevaluasi strengths and weaknesses memiliki pengaruh terhadap pengembangan obyek wisata Asrama Inggrisan sebagai heritage tourism di Kabupaten Banyuwangi.Penerapan Evaluasi faktor internal ini dilakukan dengan cara penghitungan skor tertimbang setiap faktor pada matrik yang ada.
Kemudian, masing-masing faktor kekuatan dan kelemahan dibobot menggunakan metode paired comparison (perbandingan berpasangan). Setelah itu dilakukan analisis matriks Internal FaktorEvaluation (IFE) pengembangan obyek wisata Asrama Inggrisan sebagai heritage tourism di Kabupaten Banyuwangi.

\begin{tabular}{|c|c|c|c|c|}
\hline \multicolumn{5}{|c|}{ 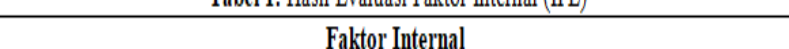 } \\
\hline $\mathrm{N}_{0}$ & Kekuatan & Bobot & Rating & Skor \\
\hline 1 & Memiliki nilai sejarah yang kental & 0.127 & 4 & 0.508 \\
\hline 2 & Terdapat bukti pembangunan telegraf bawahlaut & 0.133 & 4 & 0.532 \\
\hline 3 & Ditetapkan sebagai cagar budaya Kabupaten Banyuwangi & 0.130 & 4 & 0.520 \\
\hline 4 & Memiliki keunikan arsitektur pada bangunan & 0.131 & 4 & 0.524 \\
\hline \multicolumn{2}{|r|}{ Total } & 0.521 & & 2.084 \\
\hline $\mathrm{N}_{0}$ & Kelemahan & Bobot & Rating & Skor \\
\hline 1 & Belum ada pengelolaan dan perawatan dengan baik & 0.103 & 2 & 0.206 \\
\hline 2 & Kurang fasilitas, sarana dan prasarana & 0.099 & 2 & 0.198 \\
\hline 3 & Lingkungan terlihat kumuh & 0.088 & 2 & 0.176 \\
\hline 4 & Belum didukung oleh SDM khusus & 0.099 & 2 & 0.198 \\
\hline 5 & $\begin{array}{l}\text { Belum ada campur tangan pemerintah daerah dalam bidang } \\
\text { pengelolaan dan pengembangan }\end{array}$ & 0.091 & 1 & 0.091 \\
\hline & Total & 0.480 & & 0.869 \\
\hline & Total Skor Tertimbang & 1.00 & & 2.953 \\
\hline
\end{tabular}

Sumber Data: Hasil Proses Penelitian

Hasil analisis matriks IFE pada Tabel 1membuktikan bawha faktor kekuatan utama adalah adanya bukti pembangunan telegraf bawah laut dengan nilai skor 0.532. Faktor kelemahan utama terletak pada faktor Belum ada pengelolaan dan perawatan dengan baik dengan nilai skor 0.206. Sementara hasil skor tertimbang sebesar 2.953. Hal ini menunjukkan bahwa kemampuan faktor internal Asrama Inggrisan dalam pengembangan potensinya berada pada posisi diatas rata-rata. Total nilai tertimbang sebesar 2.084 untukfaktor kekuatan dan 0.869untuk faktor kelemahanmenunjukkan bahwa Asrama Inggrisan memiliki faktor kekuatan yang lebih besar dibandingkan faktor kelemahan.

\section{Evaluasi Faktor Eksternal}

Analisis faktor eksternal dilakukan untuk mengevaluasi peluang dan ancaman yang terkait dengan pengembangan obyek wisata Asrama Inggrisan sebagai heritage tourism di Kabupaten Banyuwangi. 
Faktor-faktor peluang yang dapat dimanfaatkan dan faktor-faktor ancaman yang harus diantisipasi oleh obyek wisata Asrama Inggrisan merupakan Faktor lingkungan eksternal yang harus diantisipasi. Evaluasi faktor eksternal dilakukan dengan menghitungrata-rata total skor tertimbang masing-masing faktor eksternal yang kemudian disusun dalam sebuah matriks evaluasi untuk masing-masing faktor. Pada matriks evaluasi tersebut, pembobotan masing-masing faktor peluang dan ancaman menggunakan paired comparison (perbandingan berpasangan). Kemudian, menggunakan matriks Evaluasi Faktor Eksternal (EFE) untuk mengetahui keadaan eksternal pengembangan obyek wisata Asrama Inggrisan sebagai heritage tourism di Kabupaten Banyuwangi.

\begin{tabular}{|c|c|c|c|}
\hline \multicolumn{4}{|l|}{ Falktor Ekssternal } \\
\hline No Peluang & Bobot & Rating & Skor \\
\hline 1 Berpeluang memiadi heritagetourisisn di masa yang akan dating & 0.125 & 4 & 0.500 \\
\hline 2 Beppotensi sebagagi destimasi wisata eduluasis sejarah & 0.127 & 4 & 0.508 \\
\hline 3 Berpeluang menajlin kerjasama dengan Pemkab Banyurvangi & 0.120 & 3 & 0.360 \\
\hline 4 Dapat meniadi aset berharga sebagai peningogalan heritage & 0.120 & 3 & 0.360 \\
\hline 5 Berpellang menadid destimasi wisata ilonik & 0.106 & 3 & 0.318 \\
\hline Total & 0.598 & & 2.046 \\
\hline No Ancaman & Bobot & Rating & Skor \\
\hline 1 Kenusakan bangunan & 0.099 & 3 & 0.297 \\
\hline 2 Terjadinya vandalism & 0.111 & 3 & 0.333 \\
\hline 3 Kebjiakan dari pimpinan yang berubah & 0.094 & 3 & 0.282 \\
\hline 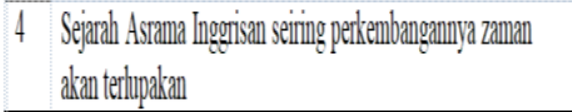 & 0.097 & 2 & 0.194 \\
\hline Total & 0.401 & & 1,106 \\
\hline Total Skor Tertimbang & 1,00 & & $3.15 \%$ \\
\hline
\end{tabular}

Berdasarkan Tabel 2 diketahui bahwa faktor peluang utama Berpotensi sebagai destinasi wisata edukasi sejarah dengan nilai skor 0.508.Faktor ancaman utama terletak pada faktor terjadinya vandalism dengan nilai skor 0.333.Total skor tertimbang dari analisi yang dilakukan sebesar 3.152. Hal ini jelas memperlihatkan bahwa kemampuan faktor eksternal Asrama Inggrisan dalam pengembangan berada pada posisi diatas rata-rata. Total nilai tertimbang untuk faktor peluang 2.046 dan untuk faktor ancaman 1.106. Dari sini dapat disimpulkan bahwa Asrama Inggrisan memiliki faktor peluang yang lebih besar dibandingkan faktor ancaman.

\section{Analisis Posisi Pengembangan Destinasi}

Setelah proses evaluasi selesai, Matriks IFE dan EFE yang telah diberikan bobot dan rating serta total skor masing-masing faktor internal dan eksternal, kemudian akan digabung pada matriks Internal Eksternal (Matriks IE). Skor yang terdapat pada IFE pada sumbu X dan skor bobot EFE total pada sumbu Y digunakan untuk melihat posisi Asrama Inggrisan, yang kemudian digunakan untuk untuk dasar acuan penetapkan strategi yang sesuai dijalankan oleh obyek wisata tersebut. Berdasarkan pada Tabel 1 dan Tabel 2diketahui bahwa total skor untuk Evaluasi Faktor Internal (IFE) sebesar2.953 dan total skor untuk Evaluasi Faktor Eksternal (EFE) sebesar3.152. Kedua hasil ini menempatkan menempatkan posisi obyek wisata Asrama Inggrisan berada pada sel II yang berarti growth and build. Padas el ini strategi yang bias diterapkan adalah intensif dan integrasi.

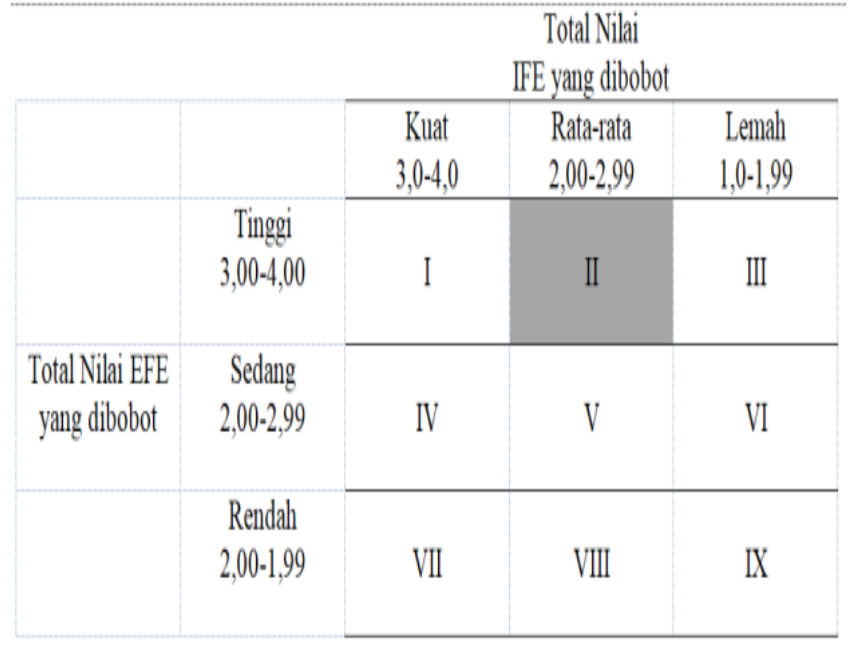

Gambar 1.1 Hasil Matriks IE (David,2012)

Perumusan Alternatif Strategi 
Salah satu cara untuk mencocokan peluang dan ancaman eksternal yang dihadapi suatu obyek wisata tertentu dengan kekuatan dankelemahan internalnya adalah dengan menggunakan matrik SWOT karena matriks SWOT merupakan suatu alat yang dapat diaplikasikan untuk mengembangkan strategi yang berkaitan dengan strategi SO (kekuatan-peluang), strategi WO (kelemahan-peluang), strategi ST (kekuatanancaman), dan strategi WT (kelemahanancaman). Setelah dianalisa menggunakan matrix SWOT, dihasilkan 10 strategi yang dalam penelitian ini, strategi tersebut antara lain:

\begin{tabular}{|c|c|c|}
\hline Falitor Elsterual & $\begin{array}{l}\text { Strengths (\$) } \\
\text { 1. Meniliki nilai sejarah yang } \\
\text { kental } \\
\text { 2. Terdapat bukti penbangunan } \\
\text { telegaf bawah laut } \\
\text { 3. Ditetapkan sabagi cagr } \\
\text { budaya Kabupaten } \\
\text { Banyuwang } \\
\text { 4. Meniliki keunilan arsiteltur } \\
\text { plda bangunan }\end{array}$ & $\begin{array}{l}\text { Weaknesses (Wi) } \\
\text { 1. Belun ada pengelolaan dan } \\
\text { perawatan dengan baik } \\
\text { 2. Kurang fasilitas, sarana dan } \\
\text { prasarana } \\
\text { 3. Lingoungan terlihatkumuh } \\
\text { 4. Belum didukung oleh SDM } \\
\text { khusus } \\
\text { 5. Belum ada canpur tangan } \\
\text { pencerintah daerah dalam } \\
\text { bidang pengelolaan dan } \\
\text { pengembangan }\end{array}$ \\
\hline 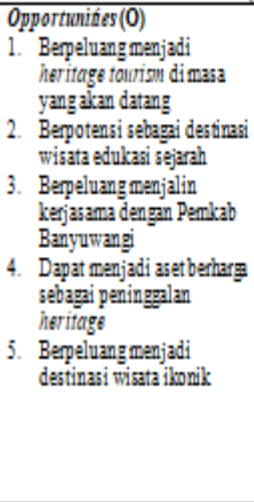 & 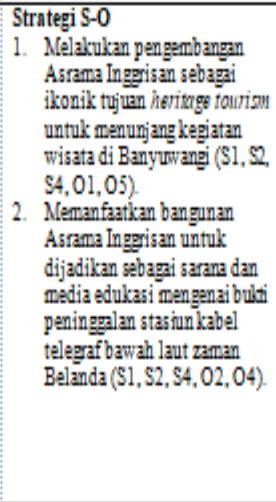 & 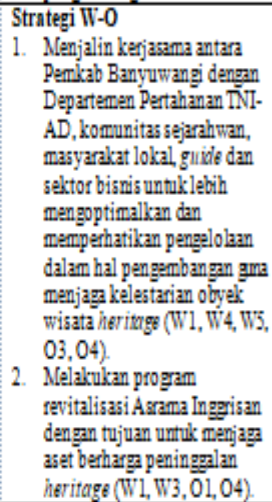 \\
\hline $\begin{array}{l}\text { Threats (T) } \\
\text { 1. Kerusakan bangunan } \\
\text { 2. Terjadinya vandowism } \\
\text { 3. Kebijakan dari pimpinan } \\
\text { yang berubah } \\
\text { 4. Sejarah Asrama Inggrisan } \\
\text { seiring perkembangannya } \\
\text { raman akan terlupakan }\end{array}$ & 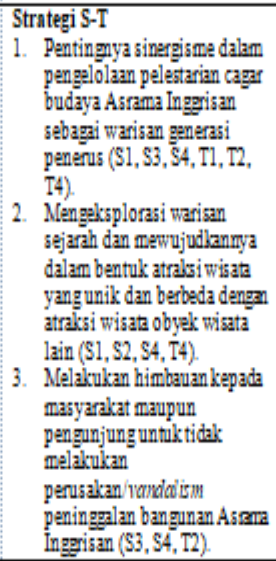 & 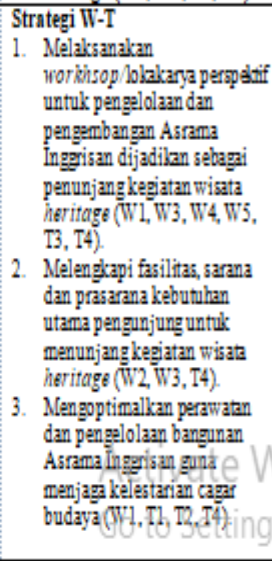 \\
\hline
\end{tabular}

Gambar 2.Perumusan alternatif strategi pengembangan

Pilihan alternative strategi pengembangan yaitu :
1. Melakukan pengembangan Asrama Inggrisan sebagai ikonik tujuan heritage tourism untuk menunjang kegiatan wisata di Banyuwangi. Pengembangan tersebut dilakukan untuk tujuan menjaga eksistensi serta kelestarian bangunan Asrama Inggrisan.

2. Memanfaatkan bangunan Asrama Inggrisan untuk dijadikan sebagai sarana dan media edukasi mengenai bukti peninggalan stasiun kabel telegraf bawah laut zaman Belanda. Adanya bangunan Asrama Inggrisan dapat dimanfaatkan untuk memperkenalkan kepada pengunjung maupun masyarakat bahwa bangunan tersebut dulunya pernah digunakan sebagai stasiun kabel telegraf bawah laut yang menjadi penghubung komunikasi antara Australia dengan Asia dan Eropa.

3. Menjalin kerjasama antara Pemkab Banyuwangi dengan Departemen Pertahanan TNI-AD, komunitas sejarahwan, masyarakat lokal, guide dan sektor bisnis untuk lebih mengoptimalkan dan memperhatikan pengelolaan dalam hal pengembangan guna menjaga kelestarian obyek wisata heritage. Tujuan dari strategi ini ialah untuk menciptakan suasana kerjasama dan koordinasi yang baik antar pihak-pihak yang terlibat dalam melakukan rencana pengembangan kawasan Asrama Inggrisan.

4. Melakukan program revitalisasi Asrama Inggrisan dengan tujuan untuk menjaga aset berharga peninggalan heritage. Program tersebut memiliki tujuan untuk memperbaiki kualitas bangunan Asrama Inggrisan serta program pengembangan kegiatan wisata yang relevan dengan bangunan Asrama Inggrisan, misalnya Asrama Inggrisan dijadikan museum Bumi Blambangan.

5. Pentingnya sinergisme dalam pengelolaan pelestarian cagar budaya Asrama Inggrisan sebagai warisan generasi penerus. Paradigma pelestarian cagar budaya saat ini tidak hanya pada tindakan mempertahankan saja, akan tetapi sudah menuntut pada tahap 
pengembangan dan pemanfaatan yang berorientasi pada kesejahteraan masyarakat.

6. Menggali lebih dalam potensi sebuah warisan sejarah dan mewujudkannya dalam bentuk atraksi wisata yang unik dan berbeda dengan atraksi wisata obyek wisata lain, misalnya membuat konsep wisata tradisional Banyuwangi tempo dulu dengan konsep bentuk bangunan Asrama Inggrisan.

7. Melakukan himbauan kepada masyarakat maupun pengunjung untuk tidak melakukan perusakan/vandalism peninggalan bangunan Asrama Inggrisan. Himbauan tersebut bertujuan agar masyarakat maupun pengunjung merasa ikut memiliki untuk menjaga kelestarian cagar budaya tersebut.

8. Melaksanakan workhsop/lokakarya perspektif untuk pengelolaan dan pengembangan Asrama Inggrisan dijadikan sebagai penunjang kegiatan wisata heritage. Tujuan diadakan workhsop/lokakarya ialah untuk menyatukan perspektif antara pemerintah, pemerintah daerah, Departemen Pertahanan TNI-AD, komunitas sejarahwan, masyarakat lokal, guide, akademisi dan sektor bisnis mengenai pengelolaan pengembangan dan pemanfaatan Asrama Inggrisan untuk kedepannya.
9. Melengkapi fasilitas, sarana dan prasarana kebutuhan utama pengunjung untuk menunjang kegiatan wisata heritage, misalnya yang utama pembangunan toilet, mushola, food court dan souvenir, penataan tempat parkir.

10. Mengoptimalkan perawatan dan pengelolaan bangunan Asrama Inggrisan guna menjaga kelestarian cagar budaya agar upaya pelestarian cagar budaya menjadi tanggung jawab bersama. Pemerintah sebagai pengemban amanah perlu melibatkan masyarakat, swasta dan lembaga-lembaga negara lainnya. Keberadaan cagar budaya memiliki arti yang penting. Kelalaian dalam melakukan pelestarian cagar budaya sama artinya dengan menghilangkan aset budaya bangsa. Hal tersebut disebabkan sifat dari cagar budaya yang mudah rusak, tidak tergantikan, tidak bisa diukur dan tidak bisa diperbaharui. Dengan demikian, upaya pelestarian mutlak untuk dilakukan, agar warisan budaya masa lalu tetap lestari, kini dan nanti di masa yang akan datang.

Tabel 1.Hasil Evaluasi Faktor Internal (IFE)

\begin{tabular}{llccc}
\hline & \multicolumn{1}{c}{ Faktor Internal } & & \\
\hline No & Kekuatan & Bobot & Rating & Skor \\
\hline 1 & Memiliki nilai sejarah yang kental & 0.127 & 4 & 0.508 \\
2 & Terdapat bukti pembangunan telegraf bawah laut & 0.133 & 4 & 0.532 \\
3 & Ditetapkan sebagai cagar budaya Kabupaten Banyuwangi & 0.130 & 4 & 0.520 \\
4 & Memiliki keunikan arsitektur pada bangunan & 0.131 & 4 & 0.524 \\
\hline \multicolumn{1}{c}{ Total } & $\mathbf{0 . 5 2 1}$ & & $\mathbf{2 . 0 8 4}$ \\
\hline No & Kelemahan & Bobot & Rating & Skor \\
\hline 1 & Belum ada pengelolaan dan perawatan dengan baik & 0.103 & 2 & 0.206 \\
2 & Kurang fasilitas, sarana dan prasarana & 0.099 & 2 & 0.198 \\
3 & Lingkungan terlihat kumuh & 0.088 & 2 & 0.176 \\
4 & Belum didukung oleh SDM khusus & 0.099 & 2 & 0.198 \\
5 & Belum ada campur tangan pemerintah daerah dalam bidang & 0.091 & 1 & 0.091 \\
\hline \multicolumn{2}{c}{ Tengelolaan dan pengembangan } & $\mathbf{0 . 4 8 0}$ & $\mathbf{0 . 8 6 9}$ \\
\hline \multicolumn{2}{c}{ Total Skor Tertimbang } & $\mathbf{1 . 0 0}$ & $\mathbf{2 . 9 5 3}$ \\
\hline
\end{tabular}


Tabel 2.Hasil Evaluasi Faktor Eksternal (EFE)

\section{Faktor Eksternal}

\begin{tabular}{|c|c|c|c|c|}
\hline No & Peluang & Bobot & Rating & Skor \\
\hline 1 & $\begin{array}{l}\text { Berpeluang menjadi heritage tourism di masa yang akan } \\
\text { dating }\end{array}$ & 0.125 & 4 & 0.500 \\
\hline 2 & Berpotensi sebagai destinasi wisata edukasi sejarah & 0.127 & 4 & 0.508 \\
\hline 3 & $\begin{array}{l}\text { Berpeluang menjalin kerjasama dengan Pemkab } \\
\text { Banyuwangi }\end{array}$ & 0.120 & 3 & 0.360 \\
\hline 4 & $\begin{array}{l}\text { Dapat menjadi aset berharga sebagai peninggalan } \\
\text { heritage }\end{array}$ & 0.120 & 3 & 0.360 \\
\hline \multirow[t]{2}{*}{5} & Berpeluang menjadi destinasi wisata ikonik & 0.106 & 3 & 0.318 \\
\hline & Total & 0.598 & & 2.046 \\
\hline No & Ancaman & Bobot & Rating & Skor \\
\hline 1 & Kerusakan bangunan & 0.099 & 3 & 0.297 \\
\hline 2 & Terjadinya vandalism & 0.111 & 3 & 0.333 \\
\hline 3 & Kebijakan dari pimpinan yang berubah & 0.094 & 3 & 0.282 \\
\hline 4 & $\begin{array}{l}\text { Sejarah Asrama Inggrisan seiring perkembangannya } \\
\text { zaman akan terlupakan }\end{array}$ & 0.097 & 2 & 0.194 \\
\hline & Total & 0.401 & & 1.106 \\
\hline & Total Skor Tertimbang & $\mathbf{1 . 0 0}$ & & 3.152 \\
\hline
\end{tabular}

Total Nilai IFE yang dibobot

\begin{tabular}{|c|c|c|c|c|}
\hline & Kuat & Rata-rata & Lemah \\
$2,00-2,99$ & $1,0-1,99$ \\
\hline & $\begin{array}{c}\text { Tinggi } \\
3,00-4,00\end{array}$ & I & II & III \\
\hline $\begin{array}{c}\text { Total Nilai } \\
\text { EFE yang } \\
\text { dibobot }\end{array}$ & $\begin{array}{c}\text { Sedang } \\
2,00-2,99\end{array}$ & IV & V & VI \\
\hline & $\begin{array}{c}\text { Rendah } \\
2,00-1,99\end{array}$ & VII & VIII & IX \\
\hline
\end{tabular}


Gambar 1.Hasil Matriks IE (David, 2012)

\begin{tabular}{|c|c|c|}
\hline & Strengths $(\mathrm{S})$ & Weaknesses (W) \\
\hline & $\begin{array}{l}\text { 1. } \begin{array}{l}\text { Memiliki nilai sejarah } \\
\text { yang kental }\end{array} \\
\text { 2. } \begin{array}{l}\text { Terdapat bukti } \\
\text { pembangunan telegraf } \\
\text { bawah laut }\end{array} \\
\text { 3. } \begin{array}{l}\text { Ditetapkan sebagai cagar } \\
\text { budayar Kabupaten }\end{array} \\
\begin{array}{l}\text { Banyuwangi } \\
\text { 4. }\end{array} \\
\begin{array}{l}\text { Memiliki keunikan } \\
\text { arsitektur pada bangunan }\end{array}\end{array}$ & $\begin{array}{l}\text { 1. Belum ada pengelolaan dan } \\
\text { perawatan dengan baik } \\
\text { 2. Kurang fasilitas, sarana dan } \\
\text { prasarana } \\
\text { 3. Lingkungan terlihat kumuh } \\
\text { 4. Belum didukung oleh SDM khusus } \\
\text { 5. Belum ada campur tangan } \\
\text { pemerintah daerah dalam bidang } \\
\text { pengelolaan dan pengembangan }\end{array}$ \\
\hline Opportunities (O) & Strategi S-O & Strategi W-O \\
\hline $\begin{array}{l}\text { 1. Berpeluang menjadi } \\
\text { heritage tourism di } \\
\text { masa yang akan datang } \\
\text { 2. Berpotensi sebagai } \\
\begin{array}{ll}\text { destinasi } & \text { wisata } \\
\text { edukasi seiarah }\end{array}\end{array}$ & $\begin{array}{l}\text { 1. Melakukan } \\
\text { pengembangan Asrama } \\
\text { Inggrisan sebagai ikonik } \\
\text { tujuan heritage tourism } \\
\text { untuk menunjang } \\
\text { kegiatan wisata di }\end{array}$ & $\begin{array}{l}\text { 1. Menjalin kerjasama antara Pemkab } \\
\text { Banyuwangi dengan Departemen } \\
\text { Pertahanan TNI-AD, komunitas } \\
\text { sejarahwan, masyarakat lokal, } \\
\text { guide dan sektor bisnis untuk lebih } \\
\text { menoontimalkan }\end{array}$ \\
\hline $\begin{array}{l}\text { 3. Berpeluang menjalin } \\
\text { kerjasama dengan } \\
\text { Pemkab Banyuwangi } \\
\text { 4. Dapat menjadi aset } \\
\text { berharga sebagai } \\
\text { peninggalan heritage } \\
\text { 5. Berpeluang menjadi } \\
\text { destinasi wisata ikonik }\end{array}$ & $\begin{array}{l}\text { Banyuwangi (S1, S2, S4, } \\
\text { O1, O5). } \\
\text { 2. Memanfaatkan bangunan } \\
\text { Asrama Inggrisan untuk } \\
\text { dijadikan sebagai sarana } \\
\text { dan media edukasi } \\
\text { mengenai bukti } \\
\text { peninggalan stasiun kabel } \\
\text { telegraf bawah laut } \\
\text { zaman Belanda (S1, S2, } \\
\text { S4, O2, O4). }\end{array}$ & $\begin{array}{l}\text { memperhatikan pengelolaan dalam } \\
\text { hal pengembangan guna menjaga } \\
\text { kelestarian obyek wisata heritage } \\
\text { (W1, W4, W5, O3, O4). } \\
\text { 2. Melakukan program revitalisasi } \\
\text { Asrama Inggrisan dengan tujuan } \\
\text { untuk menjaga aset berharga } \\
\text { peninggalan heritage (W1, W3, } \\
\text { O1, O4). }\end{array}$ \\
\hline
\end{tabular}




\begin{tabular}{|c|c|c|}
\hline Threats (T) & Strategi S-T & Strategi W-T \\
\hline $\begin{array}{l}\text { 1. Kerusakan bangunan } \\
\text { 2. Terjadinya vandalism } \\
\text { 3. Kebijakan dari } \\
\text { pimpinan yang berubah } \\
\text { 4. Sejarah Asrama } \\
\text { Inggrisan seiring } \\
\text { perkembangannya } \\
\text { zaman akan terlupakan }\end{array}$ & $\begin{array}{lr}\text { 1. Pentingnya } & \text { sinergisme } \\
\text { dalam pengelolaan } \\
\text { pelestarian cagar budaya } \\
\text { Asramarana Inggrisan } \\
\text { sebagai warisan generasi } \\
\text { penerus (S1, S3, S4, T1, } \\
\text { T2, T4). } \\
\text { 2. Mengeksplorasi warisan } \\
\text { sejarah dan } \\
\text { mewujudkannya dalam } \\
\text { bentuk atraksi wisata } \\
\text { yang unik dan berbeda } \\
\text { dengan atraksi wisata } \\
\text { obyek wisata lain (S1, } \\
\text { S2, S4, T4). } \\
\text { Melakukan himbauan } \\
\text { kepada masyarakat } \\
\text { maupun pengunjung } \\
\text { untuk tidak melakukan } \\
\text { perusakan/vandalism } \\
\text { peninggalan bangunan } \\
\text { Asrama Inggrisan (S3, } \\
\text { S4, T2). }\end{array}$ & $\begin{array}{l}\text { 1. Melaksanakan workhsop/lokakarya } \\
\text { perspektif untuk pengelolaan dan } \\
\text { pengembangan Asrama Inggrisan } \\
\text { dijadikan sebagai penunjang } \\
\text { kegiatan wisata heritage (W1, W3, } \\
\text { W4, W5, T3, T4). } \\
\text { 2. Melengkapi fasilitas, sarana dan } \\
\text { prasarana kebutuhan utama } \\
\text { pengunjung untuk menunjang } \\
\text { kegiatan wisata heritage (W2, W3, } \\
\text { T4). } \\
\text { 3. Mengoptimalkan perawatan dan } \\
\text { pengelolaan bangunan Asrama } \\
\text { Inggrisan guna menjaga kelestarian } \\
\text { cagar budaya (W1, T1, T2, T4). }\end{array}$ \\
\hline
\end{tabular}


Sadar Wisata: Jurnal Pariwisata

(p-ISSN 1858-0112, e-ISSN 15537-37677)

\section{KESIMPULAN}

Faktor yang menjadi kekuatan utama dan memiliki kepentingan relatif tertinggi adalah terdapat bukti pembangunan telegraf bawah laut.Faktor kelemahan utama yang memiliki kepentingan relatif tertinggi adalah Belum ada pengelolaan dan perawatan dengan baik.Faktor strategi peluang utama yang memiliki kepentingan relatif tertinggi adalah berpotensi sebagai destinasi wisata edukasi sejarah.Faktor strategi acaman utama yang memiliki kepentingan relatif tertinggi adalah terjadinya vandalism. Strategi yang pengembangan yang dihasilkan adalah melakukan pengembangan Asrama Inggrisan sebagai ikonik tujuan heritage tourism untuk menunjang kegiatan wisata di Banyuwangi; memanfaatkan bangunan Asrama Inggrisan untuk dijadikan sebagai sarana dan media edukasi mengenai bukti peninggalan stasiun kabel telegraf bawah laut zaman Belanda; menjalin kerjasama antara Pemkab Banyuwangi dengan Departemen Pertahanan TNI-AD, komunitas sejarahwan, masyarakat lokal, guide dan sektor bisnis untuk lebih mengoptimalkan dan memperhatikan pengelolaan dalam hal pengembangan guna menjaga kelestarian obyek wisata heritage; melakukan program revitalisasi Asrama Inggrisan dengan tujuan untuk menjaga aset berharga peninggalan heritage; pentingnya sinergisme dalam pengelolaan pelestarian cagar budaya Asrama Inggrisan sebagai warisan generasi penerus;m engeksplorasi warisan sejarah dan mewujudkannya dalam bentuk atraksi wisata yang unik dan berbeda dengan atraksi wisata obyek wisata lain; melakukan himbauan kepada masyarakat maupun pengunjung untuk tidak melakukan perusakan/vandalismpeninggalan bangunan Asrama Inggrisan; melaksanakan workhsop/lokakarya perspektif untuk pengelolaan dan pengembangan Asrama Inggrisan dijadikan sebagai penunjang
Volume 3 No.2 Desember Tahun 2020

http://jurnal.unmuhjember.ac.id/index.php/wisata

kegiatan wisata heritage; melengkapi fasilitas, sarana dan prasarana kebutuhan utama pengunjung untuk menunjang kegiatan wisata heritage; dan mengoptimalkan perawatan dan pengelolaan bangunan Asrama Inggrisan guna menjaga kelestarian cagar budaya

\section{DAFTAR PUSTAKA}

Baretto dan Giantari (2015).Strategi Pengembangan Obyek Wisata Air Panas Di Desa Maroboro.Kabupaten Bobonaro Timor Leste. E journal Ekonomi dan Bisnis, Vol. 4, No. 11, 773-796.Burns, L., Eaddy, M., A., Moore, C., Speno, L., McRae, H., T., dan Green, B. (2010), Heritage Tourism Handbook: A How to Guide for Georgia,Georgia, Amerika Serikat.

Chan, X. (2011).A SWOT study of the development strategy of Haier Group as one of the most successful Chinese enterprises. International Journal of Business and Social Science, Vol. 2, No. 11, 147-153.

David F.R. (2012). Manajemen Stretegis: Konsep,Salemba Empat, Jakarta.

Pitana, I Gede dan Gayatri, Putu G. (2005),Sosiologi Pariwisata, Andi, Yogyakarta.

Putra, A.P., Halil, Pratiwi, N. (2019). Strategi pengembangan cinderamata belerang wisata kawah Ijen Banyuwangi. Vol 21 No.1, 32-41.

Rahman, S. (2013). Heritage management challenges in historic town of Ludlow, England. World Applied Sciences Journal, Vol.24, No. 12, 1589-1596. 
Rozaan, A., Mawardi, M., K., dan Prasetya, A. (2018). Analisis Pengembangan Produk Wisata Heritage Trail Untuk Meningkatkan Citra Destinasi. Jurnal Administrasi Bisnis, Vol. 61, No. 4, 81-90.

Sulastri, A. Rifin., B. Sanim. (2018). Strategi Pengembangan Asuransi Jiwa. Jurnal Aplikasi Manajemen dan Bisnis, Vol. 4, No. 1, 44-51 